\title{
Patient-Provider-Relationship in the Hospital Care of the Elderly-A Qualitative, Multi-Perspective Study
}

\author{
Maria Rutz ${ }^{1}$, Ulrike Junius-Walker ${ }^{2}$, Marie-Luise Dierks ${ }^{1}$ \\ ${ }^{1}$ Institute of Epidemiology, Social Medicine and Health System Research, Hannover Medical School, Hannover, German \\ ${ }^{2}$ Institute of General Practice, Hannover Medical School, Hannover, German \\ Email: Rutz.Maria@mh-hannover.de,Junius-Walker.Ulrike@mh-hannover.de,Dierks.Marie-Luise@mh-hannover.de
}

How to cite this paper: Rutz, M., JuniusWalker, U. and Dierks, M.-L. (2017) PatientProvider-Relationship in the Hospital Care of the Elderly-A Qualitative, Multi-Perspective Study. Open Journal of Nursing, 7, 838-849.

https://doi.org/10.4236/ojn.2017.77063

Received: June 20, 2017

Accepted: July 24, 2017

Published: July 27, 2017

Copyright $\odot 2017$ by authors and Scientific Research Publishing Inc. This work is licensed under the Creative Commons Attribution International License (CC BY 4.0). http://creativecommons.org/licenses/by/4.0/

\begin{abstract}
For many years, there has been a growing demand for patient-centered care in inpatient settings, but a lack of clear consensus on how to exactly implement such programs. The main aim of this study was to analyze patient-centered care in the acute-care setting in a multidimensional manner from the perspectives of elderly patients, their relatives, and an independent observer. A multi-method design was used to capture the three perspectives. Passive observations and post-situational interviews with patients were integrated with semistructured interviews with patients and their relatives. 18 elderly patients and their relatives $(n=8)$ were recruited on wards for internal medicine of six hospitals. The data show significant deficits in patient-centered care in the acute-care setting. Although individual patients have different needs, certain categories of deficits emerge as universally relevant, one being the patientprovider-relationship. Patients express a desire for more frequent contact with the hospital staff. Access to doctors and nurses is particularly limited at night and on weekends. The patients are aware of these limitations and often do not draw attention to their own needs to reduce the workload on the staff. The wishes and needs of patients are not always adequately addressed. However, patients, relatives and the independent observer take positive notice of some employees because of their patient-centered attitude. The results show that there is still a need for improvement of patient-centered care. Participants from all three perspectives described differences between employees within the same institutional setting. This finding suggests that patient-centered care strongly depends on the personality of the individual caregiver.
\end{abstract}

\section{Keywords}

Patient-Provider-Relationship, Patient-Centered Care, Hospital Care, Elderly 


\section{Introduction}

Patient-centered care has been a central aspect in the international health care discussion since the 1990s [1]. Patient-centered care covers a broad range from access to care and coordination to accessible information and physical or emotional help as well as including friends and family in the care process. Patient-centered care also covers the patient-provider-relationship as one main aspect [2].

Research has shown positive effects on the perception of care due to a good patient-provider-relationship. Good communication and empathy reduce fear and stress within patients [3] [4]. There are advantages for the care-givers as well. Misunderstandings are settled faster as they are talked about earlier. And by including patients in the decision making process, doctors take pressure off themselves [5]. Nurses are more satisfied with their work and report better working relationships when a patient-centered approach is followed [6].

Although the relevance of patient-centered care has been documented more and more, patients' field reports show that it is not always abided by. The political framework and financing concepts regulate the workaday life in a hospital. Patient-centered care is thereby pushed aside. Prospectively, this topic will be fundamental because demographic changes affect the health care system. Interestingly, patients are often satisfied with their patient-care, when they rate their satisfaction via questionnaires. This is one reason why the significance of patient satisfaction surveys is discussed controversially, and why respective studies should focus on patients' experience rather than on satisfaction [2] [7] [8]. Therefore, the perspective of elderly patients and their experiences is a main subject of this study. To analyze the discrepancy between high satisfaction mentioned by the patients themselves and low patient-centered care, additional perspectives should be used to describe the care process. One of these perspectives is the view of patients' relatives. They experience the hospital stay as well, yet they are not in the same dependency as the patients. Moreover, the position of a neutral observer can generate further information related to patient-care and the patient-provider-relationship. This perspective gives an insight on possible discrepancies on what happens and what is perceived by the patients.

We explored patient-centered care from the perspective of 1) elderly patients, 2) relatives and; 3) a non-involved observer. Research questions were:

1) How do elderly patients experience the hospital care during their stay and afterwards? How do they evaluate the hospital care and which experiences are most important? Where do they see the need for improvement?

2) How do relatives experience the hospital care of their loved ones? How do they evaluate the hospital care and which experiences are the most important ones? Where do relatives see the need for improvement?

3) How does the observational perspective evaluate the hospital care of elderly patients? Which strengths and weaknesses can be detected? Is there a need for improvement? 


\section{Method}

\subsection{Study Design}

To collect data to represent the three perspectives, a multi-method-design was chosen. We integrated:

1) Theory-based, passive observation;

2) Post-situational interviews with patients and;

3) Semi-structured interviews with patients and their relatives.

For the data collection an observation guideline and an interview guideline were constructed. The categories for patient-centered-care described by the Institute of Medicine and the Picker Institute were the basis for these guidelines and complemented by further categories found in a literature review [9]-[14].

Passive observation was carried out, meaning the observer was present, but as a non-participant of patient-care. On two half days, patients were observed during specified situations, including: 1) waking up;2) meals; 3 ) ward round; 4) interventions or examinations; and 5) medical care. Additionally, there was an hour-long observation that was independent of the situation.

The researcher observed interactions among the healthcare staff, patients and relatives. Categories included: 1) information; 2) coordination; 3) team work; 4) access to care; 5) continuity; 6) patient-provider-relationship; 7) emotional support; 8) physical support; and 9) respect for personal wishes and needs.

During the observations, no tape-recorder was utilized. The observer took notes and wrote the detailed observation summaries directly afterwards.

As part of the observation, post-situational interviews were conducted with the patients during their hospital stay. These interviews were unstructured with the aim of depicting their experiences and perspectives related to the observed process. The short interviews were written down from memory.

One week after discharge, patients and relatives were interviewed to record their retrospective perception of the hospital care experience. There are several reasons why interviews took place after their discharge: patients were able to talk about the whole hospital stay; they were back in their own environment and could talk more comfortably; and patients dependency on the clinic and staff during their hospital stays did not interfere with the data collection because patients may be more cautious in their statements. The interviews were recorded.

\subsection{Study Sample}

The study was conducted on wards for internal medicine, as the main percentage of elderly patients is cared for in this setting. Six clinics were selected by the following criteria: 1) hospital owner (private, non-profit making, public); and 2) number of inhabitants where the clinic is located (city, rural area).

During the period from 10 March 2015 to 24 August 2015, 18 elderly patients and their relatives $(n=8)$ were recruited on wards for internal medicine in six hospitals. The inclusion criteria for patients were: 1) women and men; 2) age 70 years or older and; 3 ) unspecific diagnosis on admission. The unspecific diagnosis was chosen to observe the whole treatment process from having examinations 
over receiving the results and starting the treatment. The diagnosis itself was of no interest for the study as no major differences were expected. In this context, co-morbidity was not an exclusion criterion, particularly since approximately $75 \%$ of elderly patients have more than one disease. The relatives were recruited irrespective of age or gender; however they should have experienced the patient-care of the respective patient.

\subsection{Data Analysis}

Audio recorded interviews were transcribed in full. All transcribed observations and interviews were managed using MAXQDA software. We performed a qualitative content analysis. For deductive analysis, we used the categories that were the basis for the guidelines. We also searched inductively for new concepts and categories. Within-case and across-case analyses were carried out. To ensure quality of the analysis, the research team constantly discussed and refined the findings as data collection occurred.

\subsection{Ethical Approval}

The study was approved by the Ethics Committee at the Medical School Hannover (2014). All participants were informed about their rights, and given information about the purpose of the study and details of the research procedures prior to participating. Participants were allowed to withdraw from the study at any point.

Initial screening for eligible patients was conducted by hospital staff. The staff members informed the patients about the study and its goal and asked for permission to be approached by the research team. After permission was granted, the researchers provided further information.

All data were kept confidential and anonymous.

\section{Results}

\subsection{Sociodemographics}

Of the 18 patients, the majority were women with only 2 men participating. Since gender has little to no effect on the evaluation of the care, we found this difference not crucial to the results [15]. The average hospital stay was 6.72 days. One patient was transferred into a rehabilitation facility, the others went home ( $n=16)$ or to a nursing home $(n=1)$. Five patients needed to be readmissioned for either a planned surgery or because of their poor health status.

\subsection{Qualitative Findings}

Different categories of patient-centered care emerge as overly important for the patients and their relatives. One of these categories is the patient-provider-relationship which will be described in detail.

Findings reveal that the category of patient-provider-relationship can be categorized into seven main themes: 1) contact person; 2) patient as a person; 3 ) medical staff as a person; 4) comparison of medical staff; 5) professionalism; and 
6) own responsibility in the treatment process. Some of these themes, e.g. patient as a person, have further subthemes (Table 1).

1) Contact person

Continuity and knowing their contact person helps the patients to orientate themselves and remember information. It is adjuvant if the employees introduce themselves. Here, differences between the staff members can be noted. Some employees always introduce themselves and state what they are planning to do; others do not inform the patients at all. In the interviews patients talk more positively about the staff members who introduce themselves. Moreover, they recall the information given by these doctors and nurses better than from others who did not introduce themselves.

During rounds, most of the times there are more than two staff members in the patient's room. One patient reports that she is holding back on questions as she is scared to ask them with so many people present: "I wanted to, but there was a whole assembled clan. I did not dare to ask" (17). Introducing the staff members during rounds, might reduce these fears and was observed in other situations.

In the post-situational interviews the patients do not mention this theme directly. Yet, it becomes obvious that a certain continuity plays an important role for them. Doctors wearing different clothes, e.g. other colors, are not perceived as doctors. Later, the patients state that they did not get a chance to talk to a doctor. They do not recall the information those doctors have given them. Patients criticize the changing staff members in the interviews as well: "And, above all, there were always new doctors. Never the same, always different ones" (I15). This does not only mean that the patients are unable to build up a relationship, but also that they receive conflicting information from different employees. For the patients this means emotional stress and loss of trust in the treatment.

There are patients on the other hand that experience a close interaction with their treating doctors. Those patients report that responsibilities were transparent and they can depict the conversation with the doctors precisely. This confirms again that contact persons are important for the information brokerage.

Table 1. Main themes and subthemes of patient-provider-relationship.

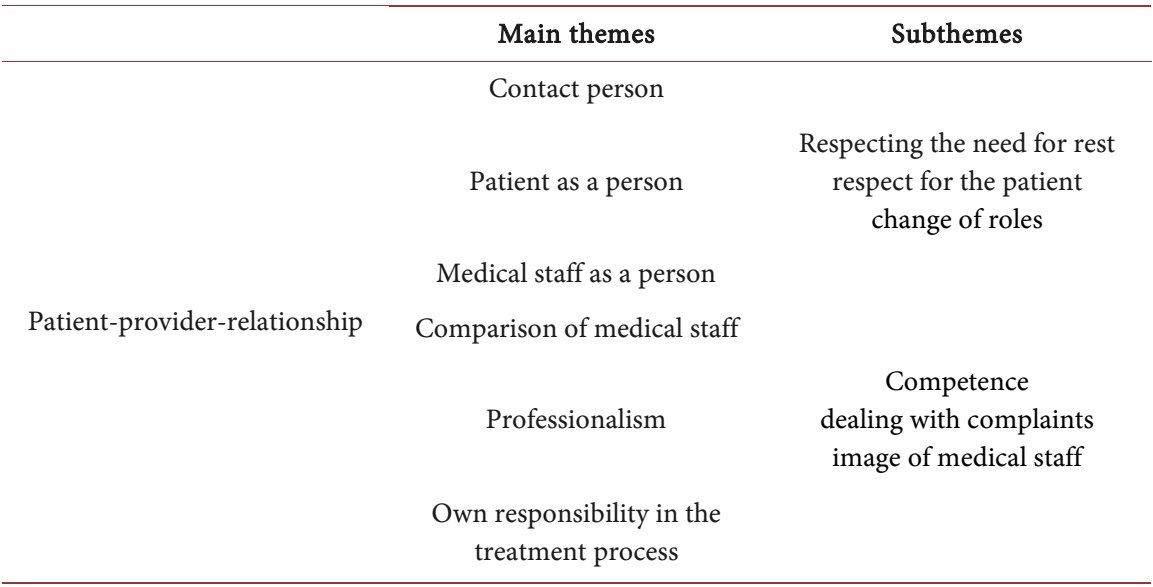


Overall, patients mainly complain about not having a doctor as a steady contact person, nurses are less relevant to them. For the relatives this topic is not as important as for the patients. Still, they confirm the heterogeneous impression. One relative reports that she was supposed to approach the treating doctor without knowing him: "I did not know his name. I could not call him" (IR1). One relative reflects the difference in her own and her mother's view: "I think it was hard for her that there were always different people. Always different doctors. There was no real contact person. That was difficult for her. Nobody had all the information, just notes from the colleagues" (IR6). In another situation she depicts that this was not a problem for her. (IR6).

2) Patient as a person

This main theme can be further divided into the following subthemes: 1) respecting the need for rest and; 2) respect for the patient.

a) Respecting the need for rest

Some employees respect the patients' need for resting, others persist on their own schedule. Subsequently, there are two observed examples: "Patient 1 lies in her bed and sleeps. Her blanket is pulled over her head. The arm sticks out from underneath. The nurse takes a blood sample and carries out the blood glucose test. Patient 1 shows no reaction and continues to sleep" $(O 1,105)$. "Patient 7 lies in bed and sleeps. The nurse asks the other patients whether patient 7 has slept poorly. The nurse speaks quietly. The other patient answers that patient 7 always says that she sleeps little. The nurse answers that in that case she will come back later and will let her rest' $(O 7,74)$. In the first example, the nurse invades the privacy of the patient and performs an invasive examination. However, this also reveals the rigid work schedule under which the employees work. In the second excerpt the nurse respects the patient's need for rest.

For patients and their relatives this theme is not very important. If so, they praise the staff members for being considerate. They do not mention any critical situations as they have been observed. The relatives state that the well-being of the patients is very important to them. However, since all have had the feeling that the patients are taken care off, they talk little about this topic.

b) Respect for the patient

Disrespectful behavior can be seen in various situations, it mainly shows nonverbally or by terminating actions hastily. The following situation occurs after the patient's transfer from his wheel-chair into bed: “The nurse's phone rings. Patient 6 takes his phone and repeats 'hello' over and over again. He seems to be confused that the phone continues to ring. The nurse says softly that it is not the patient's telephone and rolls her eyes. The nurse answers her phone and leaves the room without saying anything to patient 6 " (O6). The nurse shows her annoyance openly but does not clarify the situation for patient 6 .

Disrespect also shows when nurses say that they do not want to take care of specific patients as they are too demanding (O6), or think that the hospital stay is unnecessary: "Outside in the corridor, the nurse says [to the observer] that patient 13 only imagines her illness. She is just lazy, only lies in bed and wants to 
be coddled. In her opinion, the patients in that room can all go home" (O13).

Some employees also talk disrespectfully about patients in their presence. In the following example, two staff members discuss the upcoming move of the station with only one running elevator: "You cannot lift those patients up and down the stairs (pointing to patient 2 who is strongly adipose)" (O2). Neither for the patients nor the relatives disrespect is an important topic in the post-situational interviews or interviews.

c) Change of roles

In different situation patients and employees break out of the typical interaction patterns. The following sequence has been observed during rounds: "The patient tells that she is about to move. The chief physician answers: 'That's not possible' and laughs. After that, he says, 'But seriously, moving upsets you too much.' She must keep calm. They talk about how the patient wants to do everything on her own. The chief physician says: 'I know that from my grandpa.' His grandpa is already 93 years old and still wants to do everything himself" (O10). Both the patient and the physician leave their typical roles here, but still discuss the medical problem. With this break-out, the doctor gets further background information on the patient's life and her compliance, which can have a positive effect on the future treatment. The change of roles also creates familiarity between the patients and the staff members and creates an intimacy that goes beyond the care itself. Here an example that was observed between a nurse and a patient: "The nurse asks patient 11 if she used to bike. The patient confirms and says that nowadays it is too exhausting, especially with the mountains. Without the hills, she would love to bike. The nurse adds: 'Straight streets and tailwind'. Both laugh" (O11). Patients recall those employees as more empathetic. They do not name the role change explicitly, but describe the same situations as were observed.

3) Medical staff as person

The workload is one of the main topics the patients and relatives address. Patients express a desire for more frequent contact with the hospital staff. Particularly at night and on weekends access to doctors and nurses is limited. At the same time they are very understanding and even try to minimize the workload: "The nurse says to patient 15 that he should ring as soon as the infusion has run through. He replies that they are ringing [him and his bed neighbor] as soon as both infusions have run through. This way she only has to come once" (O15). The patients and relatives mostly talk about the nurses', rarely about the doctors' workload. The patients take sides with the nurses and defend mistakes they make. They are less forgiving when it comes to doctors and waiting for information or examinations.

\section{4) Comparison of medical staff}

Between the employees, differences in their interaction with the patient can be identified. These differences concern the communication, the handling of the patient and the care. There are employees who distance themselves from the patients. Those employees do not respond to the patients, turn away during the 
conversation, or interrupt the patients verbally or non-verbally: "The nurse says to patient 14 that she wants to take a blood sample. Patient 14 says: 'You want blood, but I get nothing to eat.' Patient 14 laughs. The nurse does not react' (O14). Other staff members are more attentive.

Patients judge employees as positive who are concerned about their worries, inquire about their welfare and respond to their needs. Positive reviews dominate in the interviews. Even though, critical situations have been observed, the patients hardly mention them: "One was very loud and the other one was very quiet. [...] But in general, they have been very nice. [...] There is always a black sheep, right?" (I2). This paragraph also shows that the expectation has a strong influence on the perception and, above all, the evaluation of the hospital stay. Patients forgive negative behaviour to some degree. This phenomenon was confirmed in other interviews.

5) Professionalism

This main theme can be further divided into the following subthemes: 1) competence; 2) dealing with complaints and; 3) image of medical staff.

a) Competence

The fact that nursing assignments are carried out by trainees without supervision, shows deficiencies in professionalism and safety. This leads to stressful situations for both, patients and employees. Whereas the competence of the physicians does not play a role for the patients, the relatives question it in some cases, for example with performed examinations: " $A C T$ must be done, you cannot see anything on an $X$-ray image. $A C T$ is the best" (IR3).

b) Dealing with complaints

Patients' complaints, e.g. about the food, are mostly ignored by the nurses. Patient 7 complains about her lunch after receiving the same meal for several days in a row: "The nurse shrugs her shoulders and leaves the room" (O2). In the interviews, patients do not criticize the staff members directly, but rather indicate that some employees are not interested in them.

c) Image of medical staff

Some patients have a clear picture of doctors in general, they call them the "god in white" (I7). This picture is accompanied by a certain age of the physicians. Patients think of younger doctors as less competent: "I also think, although she is as a ward physician, [she is] a bit unsure [...] She was very young, she has a lot to learn" (I14). Those patients find it hard to trust the doctors' orders. The relatives differentiate between the doctor's image of the younger and the older generation: "My mother has the picture of the gentlemen with glasses, a lab coat and a stethoscope hanging around his neck. [...] That is, what I believe, her image of a competent doctor. [...] The chief physician who can diagnose his patients from a distance" (IR6). To the relatives, the age of the doctors is irrelevant, receiving information and having time to talk to them is more important.

6) Own responsibility in the treatment process

Patients often talk about their own responsibility in the treatment process. 
They address a number of key issues, such as the way they talk to the medical staff: "If I ask politely, then I get a decent answer. [...] But above all, 'please' and 'thank you', you can say that. And not: 'I want that, I want that."' (I9). The relatives agree to this: "I would say, it depends a lot on the patients, how they address the people who work there" (IR1). Patients feel responsible for asking actively for information. However, many patients are scared to do so (I4). The relatives confirm this statement (IR5) and rate this as a typical problem of the elderly.

\section{Limitations}

Most of the limitations of the study are practical or resource-based. Patient caring is a complex process; therefore a multi-methods approach of observation and interviews involved different settings, multiple professions, patients and relatives. Priorities regarding the study design had to be made. The low sample size reduced the data to a manageable extent. Another limitation concerned the observation. Due to potential strain, it was not possible to follow the patients throughout the whole hospital stay. Selecting typical situations produced sufficient data and reduced the stress significantly. To increase rigor and ensure the quality of the data, regular team meetings and supervision took place.

Although, there are limitations, the study design was still quite unique as it addressed more than one view of patient-centered care. The comparison of the three perspectives illustrated a complex picture of patient-centered care.

\section{Discussion}

This study concentrated on the experience of elderly patients and their relatives. The innovative study design of comparing those two perspectives with the one of a non-involved observer helped depicting the complex picture of the care process and understanding the way patients and relatives evaluate the patientprovider-relationship. Overall, all three perspectives evaluated the patient-provider-relationship similar. Sometimes the patients and relatives were less critical compared to the observer and tended to excuse negative behaviour. In other situations, patients and relatives could not depict their reasoning in detail. In the end however, they mostly reached the same conclusion as the observer. This proves again, that the patient's and relative's opinion is valuable for identifying strengths and weaknesses in the care process.

The patient-provider-relationship is influenced by many different aspects. Contact persons are an important factor, but these are not always recognizable for the patients. To facilitate this, uniform clothing and coloring can make the individual roles and tasks more transparent and thus provide guidance for the patients [16].

Both, in the observations as well as in the interviews, differences between the employees are evident. Patients describe some employees as negative or verbal aggressive, others as caring and thoughtful. Those results can also be found in the literature [17]. These differences exist while working under the same institu- 
tional conditions. This confirms that a good patient-provider-relationship depends not only on the institutional situation but also on the attitude of the employees themselves. A reflection of one's own role seems to be critical. Studies show a positive effect on the care process when supervisors set an example and motivate staff members [18]. Therefore, it is also important to implement new concepts on management level and to consider ways of launching them together with practitioners.

The change of perspective is a theme that can be found throughout the data. Patients try to break out of the typical patient role. Hoefert (2010) explains this phenomenon with the fact that older patients perceive the contrast to the healthier nursing staff stronger than younger patients [19]. Elderly patients notice their own physical deficits since these are not present in the nursing staff. This contrast intensifies their dependency. If the patient's resources are not taken into account, this contrast increases further. It is likely that one of the reasons for the frequent role change is to minimize these differences. The role changes also show that patients do not only want to be seen in the patient's role. Breaking-out of the typical hospital roles also has a positive effect on the patient-provider-relationship. It creates familiarity between the patients and the staff members and builds up trust.

Patients are aware that their own behavior has an impact on the patient-provider-relationship. Addressing the staff members in a polite way is one of the ways to build up a positive relationship. Although many elderly patients describe asking actively for information as a further responsibility, a lot of them are scared to do so. Additionally, many patients cut back on their own needs to reduce the workload of the staff. This means that staff member need to anticipate the patient's wishes and pay more attention to possible needs, especially when it comes to the need for information.

Due to demographic changes more patients need assistance. New ways have to be found to help nurses with this additional workload. One way might be the use of electronic assistance systems. It is possible to equip patients with electronic wristbands, which localize the patient or measure both vital signs and thus detect emergencies faster. A close monitoring with electronic assistance systems might reduce the workload for the nursing staff, since they no longer have to carry out the measurements individually. This way, they find more time for the emotional care of patients.

\section{Conclusion}

The results show that there is still a need for improvement of patient-centered care, especially the patient-provider-relationship. In all three perspectives, differences between employees within the same institutional setting become obvious. This finding suggests that patient-centered care strongly depends on the personality of the individual caregiver. In the future, hospitals need to further adapt to the needs of elderly patients and their relatives. Despite these ideas of designing an advanced hospital, hospitals remain a complex system in which it is 
difficult to deviate from the routines. Changes have to be made step by step.

\section{Competing Interests}

The authors declare that they have no competing interests.

\section{Funding}

The study was funded by the Ministry of Science and Culture of Lower Saxony; Germany as part of the doctoral program GESA: Health related care for a selfdetermined life in old age-Theoretical concepts, users' needs and responsiveness of the health care system.

\section{References}

[1] Millenson, M.L. (2014) New Roles and Rules for Patient-Centered Care. Journal of General Internal Medicine, 29, 979-980. https://doi.org/10.1007/s11606-014-2788-y

[2] Jenkinson, C., Coulter, A., Bruster, S., Richards, N. and Chandol,a T. (2002) Patients' Experiences and Satisfaction with Health Care: Results of a Questionnaire Study of Specific Aspects of Care. Quality and Safety in Health Care, 11, 335-339. https://doi.org/10.1136/qhc.11.4.335

[3] Clever, S.L., Jin, L., Levinson, W. and Meltzer, D.O. (2008) Does Doctor-Patient Communication Affect Patient Satisfaction with Hospital Care? Results of an Analysis with a Novel Instrumental Variable. Health Service Research, 43, 1505-1519. https://doi.org/10.1111/j.1475-6773.2008.00849.x

[4] Soltner, C., Giquello, J.A., Monrigal-Martin, C. and Beydon, L. (2011) Continuous Care and Empathic Anaesthesiologist Attitude in the Preoperative Period: Impact on Patient Anxiety and Satisfaction. British Journal of Anaesthesia, 106, 680-686. https://doi.org/10.1093/bja/aer034

[5] Farin, E. (2010) Patientorientation in Rehablitation. Journal of Rheumatology, 73 35-41. (In German)

[6] Rose, P. and Yates, P. (2015) Patients' Outcomes Related to Person-Centred Nursing Care in Radiation Cncology: A Case study. European Journal of Oncology Nursing, 19, 731-739. https://doi.org/10.1016/j.ejon.2015.05.008

[7] Rathert, C., Wyrwich, M.D. and Boren, S.A. (2013) Patient-Centered Care and Outcomes: A Systematic Review of the Literature. Medical Care Research and Review, 70, 351-379. https://doi.org/10.1177/1077558712465774

[8] Williams, G.C., Freedman, Z. and Deci, E.L. (1998) Supporting Autonomy to Motivate Patients with Diabetes for Glucose Control. Diabetes Care, 21, 1644-1651. https://doi.org/10.2337/diacare.21.10.1644

[9] Gerteis, M., Edgman-Levitan, S., Daley, J. and Delbanco, T.L. (1993) Medicine and Health from the Patient's Perspective. In: Gerteis, M., Edgman-Levitan, S., Daley, J. and Delbanco, T.L., Eds., Through the Patient's Eyes, Jossey-Bass Publishers, San Francisco, 1-15.

[10] Jenkinson, C., Coulter, A. and Bruster, S. (2002) The Picker Patient Experience Questionnaire: Development and Validation Using Data from In-Patient Surveys in Five Countries. International Society for Quality in Health Care and Oxford University Press, 14, 353-358. https://doi.org/10.1093/intqhc/14.5.353

[11] Rathert, C., Williams, E.S., McCaughey, D. and Ishqaidef, G. (2012) Patient Perceptions of Patient-Centred Care: Empirical Test of a Theoretical Model. Health $E_{X}$ pect, 18, 199-209. 
[12] Mead, N. and Bower, P. (2000) Patient-Centredness: A Conceptual Framework and Review of the Empirical Literature. Social Science \& Medicine, 51, 1087-1110.

[13] Scholl, I., Zill, J.M., Harter, M. and Dirmaier, J. (2014) An Integrative Model of Patient-Centeredness-A Systematic Review and Concept Analysis. PLoS ONE, 9, e107828. https://doi.org/10.1371/journal.pone.0107828 http://journals.plos.org/plosone/article/file?id=10.1371/journal.pone.0107828\&type =printable

[14] Goodrich, J. (2009) Exploring the Wide Range of Terminology Used to Describe Care That Is Patient-Centred. Nursing Time, 105, 14-17.

[15] Rahmqvist, M. (2001) Patient Satisfaction in Relation to Age, Health Status and Other Background Factors: A Model for Comparisons of Care Units. International Journal for Quality in Health Care, 13, 385-390. https://doi.org/10.1093/intqhc/13.5.385

[16] Bleses, H. (2005) Patient Orientation as a Quality Feature. Berlin. (In German)

[17] Nufer, T.W. and Spichiger, E. (2011) How Do Relatives of Patients with Dementia Experience the Hospital Stay and How Do They Collaborate with Professionals? A Qualitative Study. Nursing, 24, 229-237. (In German)

[18] Ruiller, C. and van der Heijden, B.I.J.M. (2016) Socio-Emotional Support in French Hospitals: Effects on French Nurses' and Nurse Aides' Affective Commitment. Applied Nursing Research, 29, 229-236.

[19] Hoefert, H. (2010) Elderly Patients in the Hospital. In: Hoefert, H.W., Ed., Patient Orientation in the Hospital, Hogrefe, Göttingen, 161-186. (In German)

\section{Submit or recommend next manuscript to SCIRP and we will provide best} service for you:

Accepting pre-submission inquiries through Email, Facebook, LinkedIn, Twitter, etc. A wide selection of journals (inclusive of 9 subjects, more than 200 journals)

Providing 24-hour high-quality service

User-friendly online submission system

Fair and swift peer-review system

Efficient typesetting and proofreading procedure

Display of the result of downloads and visits, as well as the number of cited articles

Maximum dissemination of your research work

Submit your manuscript at: http://papersubmission.scirp.org/

Or contact ojn@scirp.org 